\title{
Anti-NMDAR encephalitis after resection of melanocytic nevi: report of two cases
}

\author{
Xun-zhe Yang ${ }^{1}$, Li-ying Cui ${ }^{1}$, Hai-tao Ren ${ }^{1}$, Tao $\mathrm{Qu}^{2}$ and Hong-zhi Guan ${ }^{1 *}$
}

\begin{abstract}
Background: Encephalitis with antibodies against N-methyl D-aspartate receptor (NMDAR) is recognized as a group of antibody-mediated neuropsychiatric syndromes, which occurs with and without a tumor association. Neoplasm may contribute to the pathogenesis of Anti-NMDAR encephalitis in tumor-positive patients. However, the underlying causes in tumor-negative patients are largely unknown. This is the first report, of which we are aware, of two cases of anti-NMDAR encephalitis after the resection of melanocytic nevus.

Case presentation: We describe 2 female patients in their 20s confirmed with anti-NMDAR encephalitis. They shared two points in common: About several weeks ( 2 weeks and 5 weeks respectively) before the initial symptom, both of them underwent a resection of melanocytic nevi; the screening tests for an ovarian teratoma and other tumors were all negative. A 25 year-old woman presented with seizure, psychiatric symptoms and behavioral change for 2 weeks. Electroencephalogram indicated electrographic seizures. Anti-NMDAR antibodies were all positive in the cerebrospinal fluid and serum. Her symptoms relieved gradually after the treatment with steroids and mycophenolate mofetil. Another patient admitted to our hospital with psychosis, behavioral change and complex partial seizure over a period of 5 months. Electroencephalogram demonstrated generalized slow activities. High titres of anti-NMDAR antibodies were both detected in the cerebrospinal fluid and serum. She responded well to the first-line immunotherapy and got substantial recovery.

Conclusion: Our cases provided an observational link between anti-NMDAR encephalitis and resection of nevi. We postulate that the exposure of certain antigen on nevus cell caused by nevi excision, which might be NMDA receptor or other mimic cross-reactive antigens, may trigger an autoimmune response resulting in encephalitis. This suggested a potential site of antigen exposure triggering the immune response in non-tumor associated anti-NMDAR encephalitis, which may lend support to elucidating the underlying immunopathological mechanisms. Further studies are expected for investigating the expression of NMDA receptor on nevus cell and evaluating the validity of this hypothesis.
\end{abstract}

Keywords: Anti-NMDAR encephalitis, Antibody, Melanocytic nevi

\section{Background}

Encephalitis with antibodies against N-methyl D-aspartate receptor (NMDAR) is recognized as a group of antibodymediated neuropsychiatric syndromes, which occurs with and without a tumor association. Neoplasm may contribute to the pathogenesis of anti-NMDAR encephalitis in tumor-positive patients. Other evidence showed that non-specific systemic infections or vaccinations could act as an adjuvant of the autoimmune response.

\footnotetext{
* Correspondence: guanhz@263.net

'Department of Neurology, Peking Union Medical College Hospital, Center of Neuroscience, Chinese Academy of Medical Sciences, Beijing 100730, China Full list of author information is available at the end of the article
}

However, the underlying causes in tumor-negative patients are still largely unknown. This is the first report, of which we are aware, of two cases of anti-NMDAR encephalitis after the resection of melanocytic nevus.

\section{Case presentation}

\section{Case 1}

A 25 year-old woman presented with seizure, psychiatric symptoms and behavioral change for 2 weeks. About 5 weeks before her first symptom, she underwent a resection of nevi on her nose in a local hospital, of which the pathological diagnosis is compound nevus confirmed by the dermatologist. Her family history was 
unremarkable. The brain magnetic resonance imaging (MRI) showed normal while the electroencephalogram (EEG) indicated electrographic seizures. For her lumbar puncture, the cerebrospinal fluid (CSF) white blood cell (WBC) count was $2 / \mu \mathrm{L}$; the CSF protein concentration, $54 \mathrm{mg} / \mathrm{dl}$. The CSF-specific oligoclonal bands were weak positive. The serum and CSF samples were tested for the antibodies to cell-surface antigens including NMDAR, leucine-rich glioma inactivated 1 (LGI1), contactinassociated protein 2 (CASPR2), $\gamma$-amino-butyric acid-B receptor (GABABR) and alpha-amino-3-hydroxy-5-methyl-4-iso-xazolepropionic acid receptors (AMPAR), using a commercial assay (Catalogue No. FA 112d-1003-1, EUROIMMUN AG, Lübeck, Germany). Anti-NMDAR antibodies were all positive in the CSF and serum. Screening with an ultrasonographic examination of her ovaries and a computed tomographic scan of her chest, abdomen, and pelvis showed no evidence of tumors. She received methylprednisolone at a dose of $1 \mathrm{~g}$ per day for 5 days. Steroids were tapered down gradually as her symptoms relieved. Mycophenolate mofetil was added as the continued immunotherapy. The follow-up is still going on.

\section{Case 2}

A girl in her 20s was admitted to our hospital with psychosis, behavioral change and complex partial seizure over a period of 5 months. A resection of nevus on her forehead was performed about 2 weeks before her admission, which was intradermal nevus on the histopathology. The brain MRI was unremarkable and the EEG demonstrated generalized slow activity. The CSF analysis revealed the WBC count was $66 / \mu \mathrm{L}$ with 99 lymphocytes and $1 \%$ monocytes, and the protein concentration level was $72 \mathrm{mg} / \mathrm{dL}$. The same tests with serum and CSF for available antibodies to cell-surface antigens were performed as previously described. High titres of anti-NMDAR antibodies were both detected in the CSF and serum. The screening tests for an ovarian teratoma and other tumors were all negative. She received one course of intravenous immunoglobulin, $2 \mathrm{~g} / \mathrm{kg}$, divided into 5 days, followed with intravenous methylprednisolone at an initial dosage of $80 \mathrm{mg}$ per day. Gradually, her psychotic symptoms resolved and she was able to follow simple commands and talk to her parents. The test for NMDAR antibody in CSF became negative afterwards while that in serum remained positive.

\section{Discussion and conclusions}

Anti-NMDAR encephalitis represents a characteristic immune-mediated and treatment responsive neuropsychiatric syndrome, with and without a tumor association. Dalmau et al. [1] reported the presence of an ovarian teratoma in over $50 \%$ of anti-NMDAR encephalitis patients. The tumor that expresses NMDA receptors may trigger the antibody response against NMDA receptors by ectopically expressing neuronal antigens and contribute to breaking immune tolerance $[2,3]$. However, they also indicated that $41 \%$ of patients with antiNMDAR encephalitis do not have a clinically detectable tumor. Therefore, the underlying causes in tumornegative patients are still largely unknown. Our cases provided an observational link between anti-NMDAR encephalitis and resection of nevi, which may provide insights into the trigger factor of immune response in non-tumor associated anti-NMDAR encephalitis.

NMDA receptors are a class of ionotropic glutamate receptors (iGluRs) that are essential for neuronal development, synaptic plasticity and cell survival. NMDA receptors are obligate heterotetramers comprising of a combination of NR1, the obligatory subunit for a functional receptor, and structurally related NR2 subunits [4]. Studies have demonstrated the NR1 subunit of NMDA receptor is also expressed on human keratinocytes, using immunohistochemistry [5, 6]. Hoogduijn et al. found that cultured melanocytes express the NMDA receptors $2 \mathrm{~A}$ and $2 \mathrm{C}$ [7]. Therefore, we postulate that the nevus cell may express NMDA receptor or other mimic cross-reactive antigens on the cell surface. Exposure of certain antigens caused by nevi excision may trigger an autoimmune response and generation of anti-NMDAR antibodies, resulting in encephalitis. This suggested a potential site of antigen exposure triggering the immune response in non-tumor associated anti-NMDAR encephalitis, which may lend support to elucidating the underlying immunopathological mechanisms. Further studies were expected for investigating the expression of NMDA receptor on nevus cell and evaluating the validity of this hypothesis.

\section{Consent}

Written informed consent was obtained from the two patients for publication of this case report and any accompanying images. Copies of the written consents are available for review by the Editor-in-Chief of this journal.

\section{Abbreviations}

MRI: Magnetic resonance imaging; EEG: Electroencephalogram;

CSF: Cerebrospinal fluid; WBC: White blood cell; NMDAR: N-methyl-D-aspartate receptors; LGI1: Leucine-rich glioma inactivated 1; CASPR2: Contactin-associated protein 2; GABABR: $\gamma$-amino-butyric acid-B receptor; AMPAR: Alpha-amino-3hydroxy-5-methyl-4-iso-xazolepropionic acid receptors; iGluRs: Ionotropic glutamate receptors.

\section{Competing interests}

The authors declare that they have no competing interests.

\section{Authors' contributions}

HZG and XZY: Concept and design of the study, acquisition of data and manuscript preparation. HTR: Laboratory tests with a broad anti-neuronal antibody panel for suspected cases. TQ: Pathological consultation of the specimen of nevi. LYC: concept and design of the study and critical manuscript revision. All authors read and approved the final manuscript. 


\section{Acknowledgements}

None

\section{Author details}

'Department of Neurology, Peking Union Medical College Hospital, Center of Neuroscience, Chinese Academy of Medical Sciences, Beijing 100730, China.

${ }^{2}$ Department of Dermatology, Peking Union Medical College Hospital,

Chinese Academy of Medical Sciences, Beijing 100730, China.

Received: 26 April 2015 Accepted: 7 September 2015

Published online: 14 September 2015

\section{References}

1. Dalmau J, Gleichman AJ, Hughes EG, Rossi JE, Peng X, Lai M, et al. Anti-NMDA-receptor encephalitis: case series and analysis of the effects of antibodies. Lancet Neurol. 2008;7(12):1091-8.

2. Dalmau J, Tuzun E, Wu HY, Masjuan J, Rossi JE, Voloschin A, et al. Paraneoplastic anti-N-methyl-D-aspartate receptor encephalitis associated with ovarian teratoma. Ann Neurol. 2007;61(1):25-36.

3. Irani SR, Bera K, Waters P, Zuliani L, Maxwell S, Zandi MS, et al. N-methyl-Daspartate antibody encephalitis: temporal progression of clinical and paraclinical observations in a predominantly non-paraneoplastic disorder of both sexes. Brain. 2010;133(Pt 6):1655-67.

4. Monyer $\mathrm{H}$, Sprengel R, Schoepfer R, Herb A, Higuchi M, Lomeli H, et al. Heteromeric NMDA receptors: molecular and functional distinction of subtypes. Science. 1992;256(5060):1217-21.

5. Morhenn VB, Murakami M, O'Grady T, Nordberg J, Gallo RL. Characterization of the expression and function of $\mathrm{N}$-methyl-D-aspartate receptor in keratinocytes. Exp Dermatol. 2004;13(8):505-11.

6. Nahm WK, Philpot BD, Adams MM, Badiavas EV, Zhou LH, Butmarc J, et al. Significance of N-methyl-D-aspartate (NMDA) receptor-mediated signaling in human keratinocytes. J Cell Physiol. 2004;200(2):309-17.

7. Hoogduijn MJ, Hitchcock IS, Smit NP, Gillbro JM, Schallreuter KU, Genever PG. Glutamate receptors on human melanocytes regulate the expression of MiTF. Pigment Cell Res. 2006;19(1):58-67.

\section{Submit your next manuscript to BioMed Central and take full advantage of:}

- Convenient online submission

- Thorough peer review

- No space constraints or color figure charges

- Immediate publication on acceptance

- Inclusion in PubMed, CAS, Scopus and Google Scholar

- Research which is freely available for redistribution 